\title{
Evaluation of the Performance Enhancement of Silicone Biofouling-release Coatings by Oil Incorporation
}

\author{
KATHRYN TRUBY ${ }^{1}$, CHRISTINA WOOD $^{1}$, JUDITH STEIN ${ }^{1}$, JAMES CELLA $^{1, *}$, \\ JOHN CARPENTER ${ }^{2}$, CHRISTOPHER KAVANAGH ${ }^{3}$, GEOFF SWAIN ${ }^{3}$, DEBORAH WIEBE $^{4}$, \\ DAVID LAPOTA ${ }^{5}$, ANNE MEYER ${ }^{6}$, ERIC HOLM ${ }^{8}$, DEAN WENDT ${ }^{7}$, CELIA SMITH $^{7}$ \\ and JEAN MONTEMARANO ${ }^{8}$ \\ ${ }^{1} G E$ Corporate Research and Development, K1-4B33, One Research Circle, Niskayuna, NY 12309, USA; \\ ${ }^{2}$ GE Industrial Systems, Fort Edward, NY 12828, USA; ${ }^{3}$ Florida Institute of Technology, Melbourne, FL 32901, USA; \\ ${ }^{4}$ Bridger Scientific, Inc., Boume, MA 02532, USA; ${ }^{5}$ SPAWAR Systems Center, San Diego, CA 92152, USA; \\ ${ }^{6}$ University at Buffalo, Buffalo, NY 14214, USA; ${ }^{7}$ University of Hawaii, Honolulu, HI 96813, USA; \\ ${ }^{8}$ NSWCCD, Bethesda, MD 20084, USA
}

In response to increased evidence of ecosystem damage by toxic antifouling paints, many researchers have developed nontoxic silicone fouling release coatings. The fouling release capability of these Systems may be improved by adding nonbonding silicone oils to the coating matrix. This idea has been tested by comparing the adhesion strength of hard- and soft-fouling organisms on a cured polydimethylsilicone (PDMS) network to that of the same network containing free polydimethyldiphenylsilicone (PDMDPS) oil at five exposure sites in North America and Hawaii. Fouling coverage is discussed, together with the bioadhesion data, to emphasize that although these coatings foul the fouling is easily removed. The partitioning of the incorporated oil upon exposure of the coatings to a simulated marine environment containing sediment was determined. Less than $1.1 \mathrm{wt} \%$ of the incorporated oil was lost from the coating over one year, and the toxicity of these coatings was shown to be minimal to shrimp and fish. Brush abrasion wear was greater for coatings containing free oil, but the modulus of elasticity was not appreciably decreased by the addition of $10 \mathrm{wt} \%$ free oil.
Keywords: fouling release; coatings; silicone; oil incorporation; toxicity; barnacle adhesion

\section{INTRODUCTION}

The control of biofouling settlement on underwater surfaces such as boat hulls and power plant cooling water intakes is a problem that has been tackled using many different technologies. The most common methods of controlling biofouling include thermal treatment, chlorination, filtration, and toxic paints. Some current biofouling-control paint technology uses copperand organotin-containing antifouling paints. The mechanism of action is based on deterring fouling organisms before they attach (Bleile \& Rodgers, 1989). Although organotin-containing coatings 
are highly effective, they are also dangerous to the marine environment because the tin leachates can poison non-target organisms such as fish, vegetation, and marine mammals (Stebbing, 1985; Kannan et al., 1997). Because of increased evidence of ecosystem damage in areas close to concentrated use of tin-containing paints (Cleary \& Stebbing, 1985), application of these antifouling paints is being restricted and in some cases prohibited (Walker, 1998).

Fouling release coating technologies are currently under development in response to the need for a non-toxic coating alternative to antifouling paints. Fouling organisms may grow on the surfaces of these coatings but adhere poorly and can be removed by light brushing, water spray, or by hydrodynamic self-cleaning. The two leading biofouling release candidates have been fluoropolymers and silicones, a choice based on the observed relationship between free surface energy and "non-stick," easy-release characteristics. However, silicone polymers have shown better fouling release capability than fluoropolymers and other coatings (EPRI, 1989). This has been attributed to their being within an optimum range of critical surface tension, which is related (but not equal) to surface energy (Goupil et al., 1973; Meyer et al., 1995). Other characteristics thought to enhance the superior fouling release ability of silicones are their surface structure, rheology, and extremely low glass transition temperature $\left(\mathrm{T}_{\mathrm{g}}\right)$ as reflected in their molecular mobility (Bausch \& Tonge, 1996; Brady 1997).

One method for the enhancement of the performance of silicone fouling release polymers has been oil incorporation. The earliest example was provided by Milne (1977a; 1977b), in which a polymethylphenylsiloxane oil was incorporated into a polymethylphenylsilicone matrix. Callow et al. (1988) reported that panels that had been coated with RTV silicone elastomers containing methylphenylsilicone oils and exposed on a raft near Singapore had improved antifouling performance relative to coatings without oil. The improvement in fouling release due to the inclusion of oil is also related to the functionality of the silicone matrix into which it has been incorporated; methyl oils better enhance fouling release in phenyl-functional networks than in methyl-functional networks. (Edwards et al., 1994; Nevell et al., 1996).

Incorporation of incompatible oils may allow detachment by slippage as an additional release mechanism (Newby et al., 1995). It has been postulated that the surface structure of silicone fouling release coatings is changed when the nonbonded oils migrate to the coating surface and increase its "slipperiness." Oils that increase the hydrophobicity of the silicone surface, such as phenyl-containing oils, improve the fouling release capability of the coating (Milne \& Callow, 1985; Edwards et al., 1994). The synergistic effect of oils in a silicone matrix does not occur when the oils are incorporated into an organic matrix (Finzel \& Vincent, 1996). This may be attributed to the high flexibility of the PDMS backbone, which allows oils to freely diffuse in and out of a PDMS network (Rice et al., 1988).

In this paper the benefits of PDMDPS oil inclusion in a PDMS network are quantified. The performance of a PDMS topcoat has been compared with that of the same network containing 10 wt\% free PDMDPS oil. The coating formulations were evaluated in terms of fouling coverage, fouling adhesion strength, environmental impact, toxicity, abrasion resistance, tensile modulus, and surface properties. Fouling coverage and adhesion were evaluated differently at each exposure site, therefore, no intersite comparison is implied in the data presented.

\section{MATERIALS AND METHODS}

\section{Panel Preparation and Field Exposure Studies}

Two silicone fouling release coatings were evaluated in this study, viz. RTV11 ${ }^{\circledR}$, a PDMS elastomer obtained from GE Silicones, and 
RTV11 ${ }^{\circledR}$ amended with 10 wt\% SF1154 ${ }^{\circledR}$ a PDMDPS oil also obtained from GE Silicones. The oil does not bond into the network upon cure. These coatings were applied as the topcoat of the NRL duplex fouling release coating system (Griffith, 1992), which consists of an anticorrosive epoxy layer, a toughening silicone-styrene butylacrylate copolymer tielayer, and the silicone topcoat. The coatings were applied to $25.4 \mathrm{~cm} \times 30.5 \mathrm{~cm}$ (10 in $\times 12$ in) steel panels using standard airless spray equipment. The wet film thickness of the silicone topcoat was $0.25-0.30 \mathrm{~mm}(10-12 \mathrm{mil})$. Two panels (four sides) were submitted for exposure at five sites, viz. the Florida Institute of Technology (FIT) exposure and testing platform in the Indian River Lagoon, Florida (subtropical estuarine), the Miami Marine Research and Testing Station (MMRTS) in Biscayne Bay, Florida (subtropical estuarine), the University of Hawaii Ford Island Test Site, Hawaii (tropical marine), and two coastal (temperate estuarine) fossilfueled utility sites in the Northeastern United States (NE site 1 and NE site 2). The panels at FIT, MMRTS, and University of Hawaii were submitted in July 1997, December 1996, and August 1997, respectively. Panels at the Northeastern sites were submitted in July 1997 but were cleaned back and re-immersed at the end of the fouling season in November 1997. All panels were still in test in August 1999.

Fouling coverage at all sites was determined using ASTM method D3623 or a modification thereof. This study focused on barnacles, oysters, and calcareous tubeworms (polychaete worms with calcareous tubes). Coverage by slimes and soft fouling such as sponges and algae was also recorded.

The shear adhesion strengths of barnacles, tubeworms, and oysters to the silicone coatings were measured using ASTM method D5618, in which a force is applied parallel to the base of a hard fouling organism until the organism detaches. The adhesion strength of both adherent slimes and soft fouling organisms was measured using a test in which a jet of water was applied to the surface of the coating at incrementally increasing pressures. The procedure is described in detail in Swain et al. (1992) and Swain and Schultz (1996).

\section{Laboratory Studies}

Contact angle measurements and cleaning with a rotating brush were performed to determine surface characteristics and abrasion resistance according to literature methods (Baier \& Meyer, 1992; Meyer et al., 1994; 1997).* Contact angle measurements were made on a Ramé-Hart NRL100 goniometer. Critical surface tensions were calculated using Zisman plots. Dispersive and polar components of the critical surface tension were calculated using the Kaelble technique of paired contact angles (Kaelble, 1970). The modulus of elasticity was measured on 1-1.5 mm-thick cured sheets of the topcoat on a Rheometrics Solids Analyzer model RSAII in tensile mode. Room temperature stress-frequency sweeps from $0.1-100 \mathrm{~s}^{-1}$ were carried out at a strain of $0.5 \%$

\section{Environmental and Toxicity Studies}

Since the environmental impact of these coatings is of primary importance, both the depletion of the oil from the coating into the marine environment and the toxicity of the coatings were evaluated. To determine the depletion of nonbonded oils from the silicone topcoat, radiolabeled oils were synthesized having the same composition as the oils added to the coatings used in the field. A preliminary report on the experimental design has been published (Carpenter et al., 1998). The use of radiolabeled oils simplified the depletion rate

\footnotetext{
* The depth of wear relative to reference points outside of the brush path was measured using a Starrett model $25-441$ depth gauge.
} 
analysis since the presence of topcoat components in water and sediment was easily analyzed using radiometric detection. All radiolabeled syntheses were performed by Wizard Laboratories, West Sacramento, California. The radiolabeled precursor to PDMDPS oil consisted of a ${ }^{4} \mathrm{C}$-labeled octamethylcyclotetrasiloxane $\left(D_{4}\right)$, which was prepared by the reaction of tetrachlorotetramethylcyclotetrasiloxane with ${ }^{14} \mathrm{C}$ labeled methyl Grignard reagent.

The ${ }^{14} \mathrm{C}-\mathrm{D}_{4}$ starting material was equilibrated with octaphenylcyclotetrasiloxane $\left(D_{4}^{\text {ph }}\right)$ and dodecamethylpentasiloxane $\left(\mathrm{MD}_{3} \mathrm{M}\right)$ in the presence of potassium trimethylsilanolate. A $50 \mathrm{ml}$ one-neck round-bottom flask equipped with a magnetic stir bar and a condenser with a nitrogen inlet was charged with $2.0 \mathrm{~g}(6.8 \times$ $10^{-3} \mathrm{~mol}$ ) of a mixture of ${ }^{14} \mathrm{C}$-labeled and unlabeled $\mathrm{D}_{4}\left(5 \mathrm{mCi}\right.$ total), $3.80 \mathrm{~g}\left(9.9 \times 10^{-3} \mathrm{~mol}\right)$ $\mathrm{MD}_{3} \mathrm{M}, 4.20 \mathrm{~g}\left(5.3 \times 10^{-3} \mathrm{~mol}\right) \mathrm{D}_{4}^{\mathrm{ph}}$, and $100 \mu \mathrm{l}$ of a solution of potassium trimethylsilanolate in methyl sulfoxide $\left(3.4 \times 10^{-5} \mathrm{~mol}\right.$ potassium trimethylsilanolate). The flask was heated to $170^{\circ} \mathrm{C}$ for $6 \mathrm{~h}$ while stirring under nitrogen (only a gentle flow or a blanket). After this time, the reaction mixture was cooled to room temperature, then $30.2 \mathrm{mg}\left(3.4 \times 10^{-5} \mathrm{~mol}\right)$ of phosphoric acid in the form of silyl phosphate was added and the contents stirred for a minimum of $30 \mathrm{~min}$ at room temperature. The resulting oil was then vacuumdistilled at a temperature of $250^{\circ} \mathrm{C} / 0.03 \mathrm{mmHg}$ for $3 \mathrm{~h}$ to remove volatiles. The flask was cooled to room temperature and a clear fluid was obtained (70\% yield). GPC analysis provided $M_{w}=1,256 \mathrm{Da}, M_{n}=811 \mathrm{Da}, \mathrm{M}_{\mathrm{w}} / \mathrm{M}_{\mathrm{n}}=1.55$. The composition was confirmed by ${ }^{13} \mathrm{C}$ NMR, ${ }^{29} \mathrm{Si}$ NMR and ${ }^{1} \mathrm{H}$ NMR spectroscopies.

Aluminum strips coated with epoxy were weighed and then painted with a mixture of PDMS (using dibutyltindilaurate at $0.5 \mathrm{wt} \%$ loading as the cure catalyst) and $10 \mathrm{wt} \%{ }^{14} \mathrm{C}$-labeled PDMDPS oil. The PDMS was allowed to cure for 1 week, after which the aluminum strips were weighed to determine the total amount of silicone topcoat (PDMS plus oil) applied to each strip. Assuming a uniform distribution of ${ }^{14} \mathrm{C}$ labeled oil throughout the PDMS, the amount of ${ }^{14} \mathrm{C}$-labeled oil in each strip was calculated. The strips were then soaked in water for several days to leach out the tin. The tin rinse water was analyzed for total ${ }^{14} \mathrm{C}$ by liquid scintillation analysis to account for any radiolabeled oil that may have leached out of the coating.

The painted aluminum strips were suspended in fish tanks containing salt water and marine sediment. Marine sediment with a pH of 7.9 was obtained from Tampa Bay, Florida. A 3-gallon glass fish tank was utilized which contained 61 of distilled water, $31.3 \mathrm{ml}$ of Instant Ocean ${ }^{\circledR} 1^{-1}$ of water, and $305.25 \mathrm{~g}$ of sediment (based on sediment dry weight). The tank was maintained in the dark, and the water stirred from overhead to simulate movement of a boat through water. The temperature range of the water was $18-22^{\circ} \mathrm{C}$ over the course of the experiment. The salinity of the system was $30 \%$ and the $\mathrm{pH}$ was approximately 8.0. The volume of water was kept constant to maintain these characteristics.

Each month, one aluminum strip was removed and the amount of ${ }^{14} \mathrm{C}$-labeled oil remaining in the PDMS was determined by thermal oxidation. This process involved combusting $50-200 \mathrm{mg}$ samples of the silicone topcoat in a Packard Model 307 sample oxidizer. Any ${ }^{14} \mathrm{C}$-labeled oil was oxidized to ${ }^{14} \mathrm{CO}_{2}$, trapped in a liquid scintillation cocktail, and analyzed using an LKB-Wallace Model 1214 Rackbeta liquid scintillation counter. Based on the average of 3-5 samples per aluminum strip, the amount of ${ }^{14} \mathrm{C}$-labeled oil $\mathrm{g}^{-1}$ of silicone topcoat was determined. The total amount of oil in each aluminum strip was then calculated, based on the total weight of the silicone topcoat for a given aluminum strip. Each month, the amount of ${ }^{14} \mathrm{C}$ in the water and sediment was determined by liquid scintillation analysis and thermal oxidation/liquid scintillation analysis, respectively.

The toxicity of the silicone matrix and oils to mysid shrimp (Mysidopsis bahia) and silverside fish (Menidia beryllina) was determined using the 
EPA-600/4-87/028 standard toxicity test. In these experiments, samples of the silicone coatings with dimensions $3.8 \mathrm{~cm} \times 3.8 \mathrm{~cm} \times 0.19 \mathrm{~cm}$ were placed in seawater for each day of the 4-d EPA test.

\section{RESULTS AND DISCUSSION}

\section{Coverage of Macrofouling Organisms}

In order to quantify the effect of oil inclusion on fouling coverage, panels coated with the PDMS network with and without $10 \mathrm{wt} \%$ PDMDPS oil were immersed at MMRTS, University of Hawaii, and the two Northeastern sites. At all of the exposure sites, total coverage was slightly less for the PDMS coatings containing PDMDPS oil (Figure 1). This is also illustrated in Figure 2, which shows photographs of the panels coated with the two formulations and exposed for approximately one year at the University of Hawaii site. The decrease in total coverage is consistent with results reported by Callow et al. (1988). Because only two to four panels were exposed and evaluated at each site, there were insufficient data to calculate standard deviations. The data presented in Figure 1 represent single

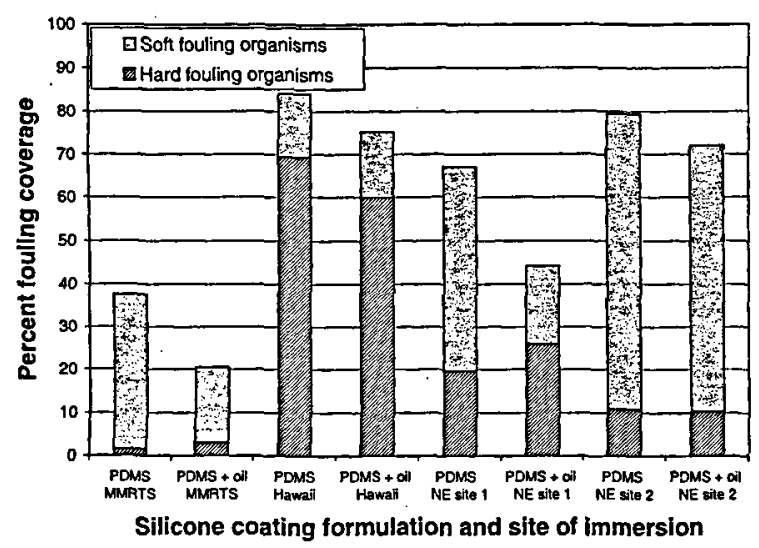

FIGURE 1 Effect of silicone coating formulation on the percentage coverage of fouling organisms at 4 exposure sites. Panels at the MMRTS and University of Hawaii sites were exposed for approximately 2 years; the NE coverage consists of data from the 1998 fouling cycle. No inter-site comparison regarding fouling coverage is implied. data points taken at the maximum coverage over one fouling cycle. Maximum coverage was obtained in May 1998 at MMTRS, in February 1999 at the University of Hawaii, and in August and November 1998 at NE sites 1 and 2, respectively. Temporal variations in fouling coverage will be the subject of a subsequent paper.

\section{Measurement of Adhesion Strength of Barnacles}

Previous research suggested that incorporation of silicone-incompatible PDMDPS oil in a PDMS network reduced total coverage and may enhance ease of removal of fouling (Truby et al., 1999). This expectation was confirmed in the barnacle adhesion data from FIT, which showed that the addition of PDMDPS oil to the PDMS network significantly decreased barnacle adhesion strength (Figure 3). Of the sites at which these coatings were evaluated, barnacles settled only at FIT. Because of its incompatibility with the PDMS topcoat, it is proposed that PDMDPS oil migrates to the surface of the silicone coating and improves its "slipperiness," thereby decreasing barnacle adhesion strength.

\section{Measurement of Adhesion Strength of Oysters and Tubeworms}

At the University of Hawaii, neither oyster nor tubeworm adhesion strength was significantly decreased by oil incorporation (Figure 4). At FIT, tubeworm adhesion strength also was not significantly affected, but oyster adhesion strength decreased by approximately one-third. Thus, the benefits of oil addition depend on the organisms to which the coating is exposed; barnacles and oysters at FIT showed the only significant decrease in adhesion strength when free oil was included in the topcoat formulation. It should be noted that the oyster and tubeworm species are different at the FIT and University of Hawaii sites. 


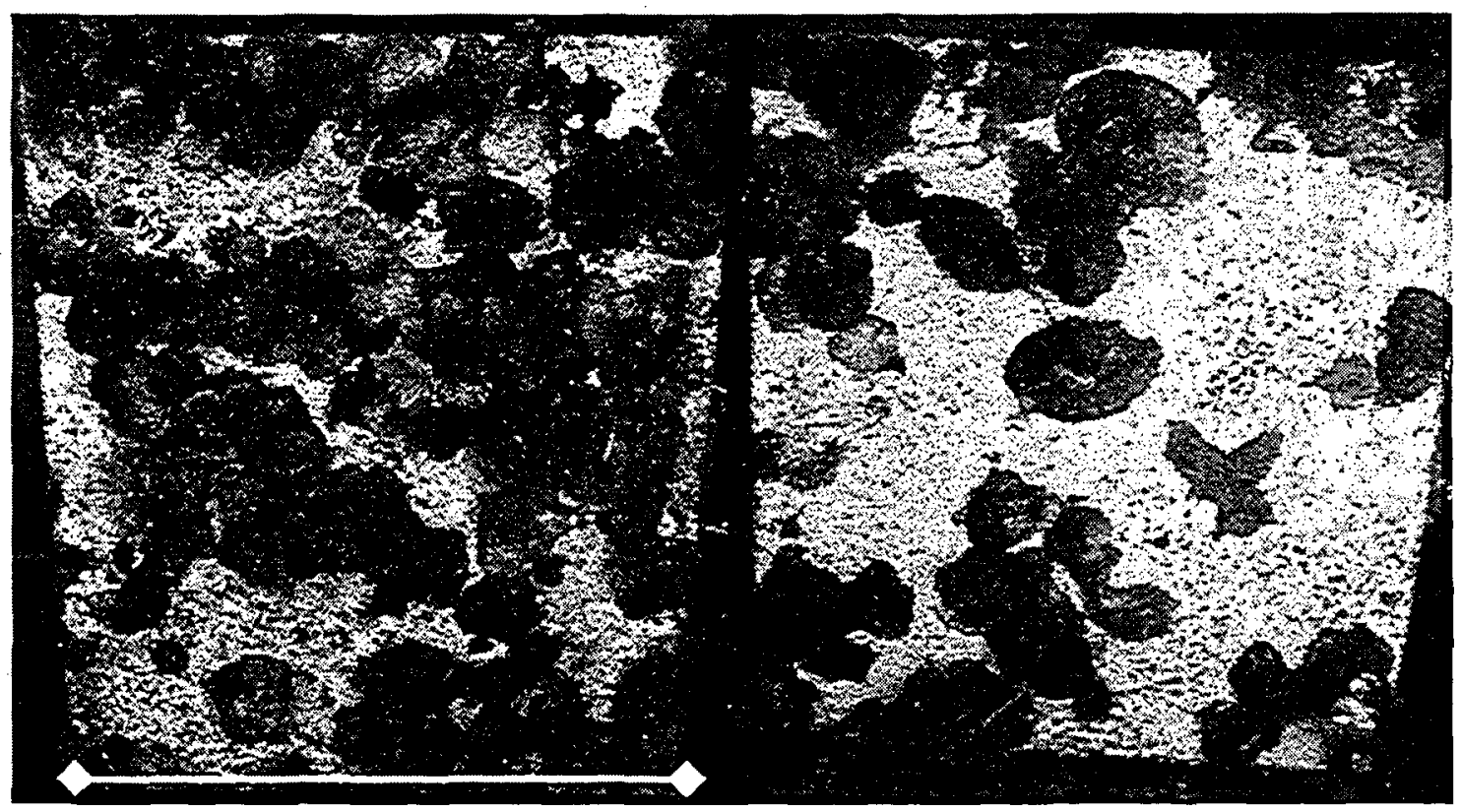

FIGURE 2 Photographs of panels exposed at the University of Hawaii fouled with oysters and soft fouling organisms. The panel on the left was coated with the PDMS topcoat, and the panel on the right was coated with the PDMS topcoat with added PDMDPS oil. Scale bar $=25.4 \mathrm{~cm}$. (See Color Section.)

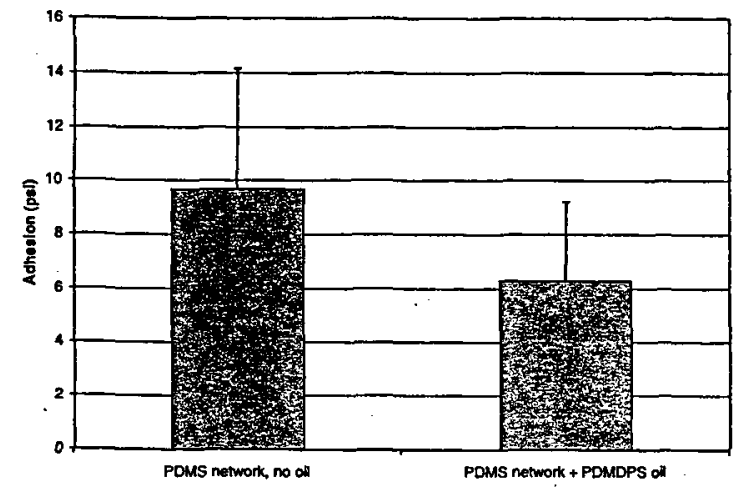

FIGURE 3 Effect of PDMDPS oil addition on mean barnacle adhesion strength at the FIT site. Error bars $=$ SDs. $P$-value $=0.000 ; n=530$.

\section{Removal of Slimes and Soft Fouling by Waterjet}

Incorporation of oil had no effect on waterjet adhesion strength of adherent slimes (bacteria and algae) and soft fouling organisms at University of Hawaii (Figure 5). Similar results were obtained at FIT.

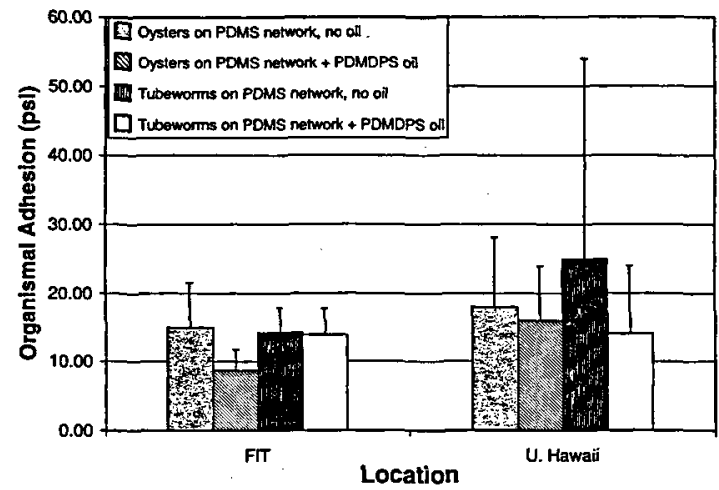

FIGURE 4 Effect of silicone coating formulation on the adhesion strength of oysters and tubeworms. Error bars = SDs. No comparison of adhesion strength across sites is implied. For oyster adhesion at FIT, $p=0.021, n=19$. For tubeworm adhesion at FIT, $p=0.734, n=43$. For oyster adhesion at the University of Hawaii, $p=0.295, n=58$. For tubeworm adhesion at the University of Hawaii, $p=0.211$, $n=43$.

\section{Coating Characterization}

Contact angle measurements were obtained on the two silicone coatings before and after $30-\mathrm{d}$ 
water immersion (Table I). The coating was cleaned of biofilm prior to post-exposure testing. The error in the composite critical surface tension was $\pm 0.5 \mathrm{mN} \mathrm{m}^{-1}$, and the error in the dispersive and polar composite components was $\pm 1.5 \mathrm{~m} \mathrm{~N} \mathrm{~m}^{-1}$. The pre-immersion critical surface tensions of the two formulations were similar, as were the polar and dispersive components of the critical surface tension. After immersion, the polar component increased for both coatings; however, the polarity of the PDMS topcoat with PDMDPS oil was approximately half that of the PDMS topcoat itself. Thus, coatings without oil incorporation underwent substantial changes in surface chemistry upon water immersion; oil mitigated this effect.

It is known that silicone coatings foul and that methods such as brush cleaning must be employed periodically to return the coatings to

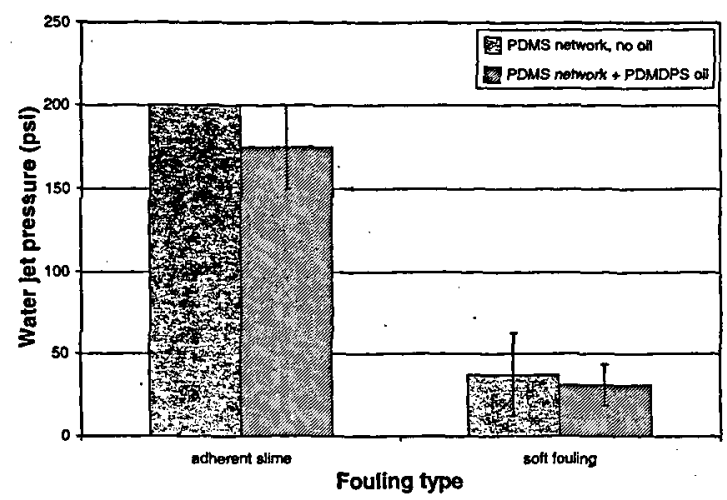

FIGURE 5 Comparison of slime and soft fouling adhesion strength measured by water jet testing at the University of Hawaii (419d exposure). For adherent slime, $p=0.356, n=4$; for soft fouling, $p=0.670, n=4$. their pre-exposure state. The resistance of the coating to abrasion was evaluated with a rotating brush and the abraded depth was profiled as a function of the number of brush strokes. The PDMS coating containing $10 \mathrm{wt} \%$ PDMDPS oil was more susceptible to wear than the PDMS coating with no oil (Figure 6). The fouling release capability has been shown to be optimum in a critical surface tension range of $20-30 \mathrm{mN}^{-1} \mathrm{~m}$ (Baier, 1980); the coatings evaluated here remain in that range even after abrasion. No significant change in contact angle was noted as a function of abrasion depth, which implies that no decrease in fouling release properties after cleaning should be anticipated.

The modulus of elasticity (in tension) of the cured PDMS matrix with and without PDMDPS oil was $1.44 \mathrm{MPa}$ and $1.19 \mathrm{MPa}$, respectively. The error in the measurements was $\pm 0.0329 \mathrm{MPa}$.

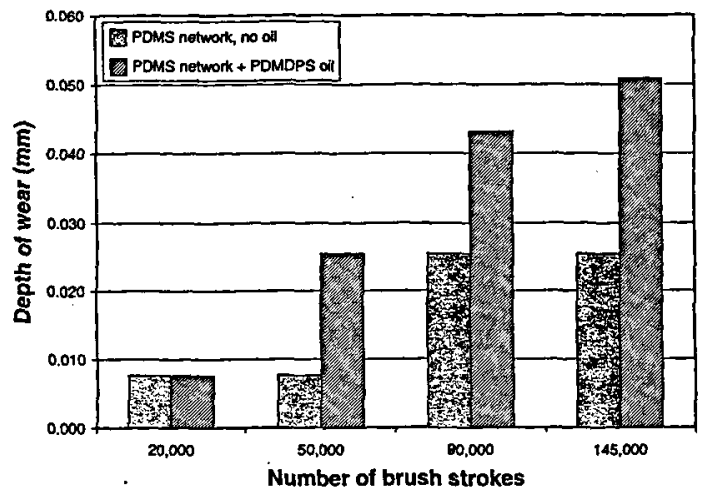

FIGURE 6 Depth of wear of silicone coatings as a function of number of brush strokes.

TABLE I Critical surface tension and the dispersion and polar composite components of free surface energy of silicone coatings before and after freshwater immersion

\begin{tabular}{lccccc}
\hline Topcoat & $\begin{array}{c}\gamma \mathrm{c} \\
\left(\mathrm{mN} \mathrm{m}^{-1}\right)\end{array}$ & $\begin{array}{c}\gamma \mathrm{d} \\
\left(\mathrm{mN} \mathrm{m}^{-1}\right)\end{array}$ & $\begin{array}{c}\gamma \mathrm{p} \\
\left(\mathrm{mN} \mathrm{m}^{-1}\right)\end{array}$ & $\begin{array}{c}\gamma \mathrm{s} \\
\left(\mathrm{mNm}^{-1}\right)\end{array}$ & $\% \gamma$ in $\gamma \mathrm{s}$ \\
\hline PDMS & 22.9 & 22.7 & 2.4 & 25.1 & 10 \\
PDMS (immersed) & 23.5 & 24.0 & 13.9 & 37.9 & 37 \\
PDMS + PDMDPS oil & 22.1 & 23.2 & 4.3 & 27.5 & 16 \\
PDMS + PDMDPS oil & 23.4 & 24.3 & 6.5 & 30.8 & 21 \\
(immersed) & & & & \\
\hline
\end{tabular}


The decrease in the modulus of elasticity mirrored the observed decrease in abrasion resistance with oil inclusion.

\section{Environmental Partitioning of Oil-containing Silicone Topcoats}

The synthetic procedure of the radiolabeled oil used to assess the environmental fate of the oil in PDMDPS amended silicone topcoats is shown below.

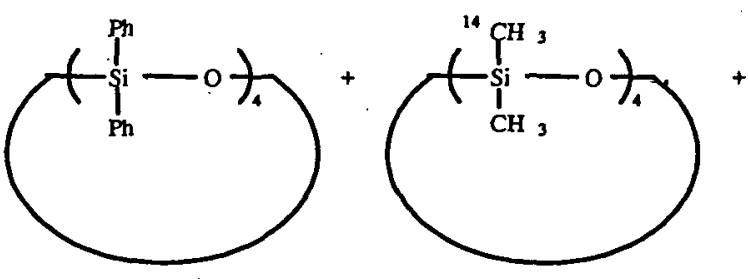

oil depleted very slowly from the PDMS matrix in the simulated marine system. The extremely low loss of ${ }^{14} \mathrm{C}$-PDMDPS from this coating suggested that oil-amended silicone fouling release coatings will not cause a significant accumulation of silicone oils in the marine environment. This result also indicates that any decrease of biofouling release efficacy cannot be attributed to loss of silicone oil from the topcoat via diffusion.

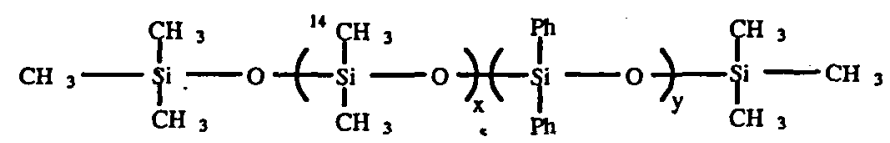

Analysis of the resultant oil by ${ }^{29} \mathrm{Si}$ NMR revealed a dimethylsiloxy:diphenylsiloxy ratio of 46.7 : 53.3 (wt: wt) with $10.5 \%$ trimethylsiloxy endgroups. The ${ }^{29} \mathrm{Si}$ NMR spectrum of the oil is shown in Figure 7.

The radiolabeled oil was then mixed with the PDMS network and painted onto coupons. After cure, the coupons were suspended in a simulated marine environment. Depletion of the oil from the coupons over a 1-year period and partitioning into the water and sediment were determined. After 12 months in salt water, $<1.1 \%$ and $\leq 0.08 \%$ of the total ${ }^{14} \mathrm{C}$-PDMDPS was detected in the water and sediment, respectively (Figure 8). Over the 12-month period, the combined weight percent of PDMDPS in the topcoat, the water, and the sediment was $100.65 \% \pm 6.5 \%$ of the total ${ }^{14} \mathrm{C}$ introduced into the system. Thus. PDMDPS

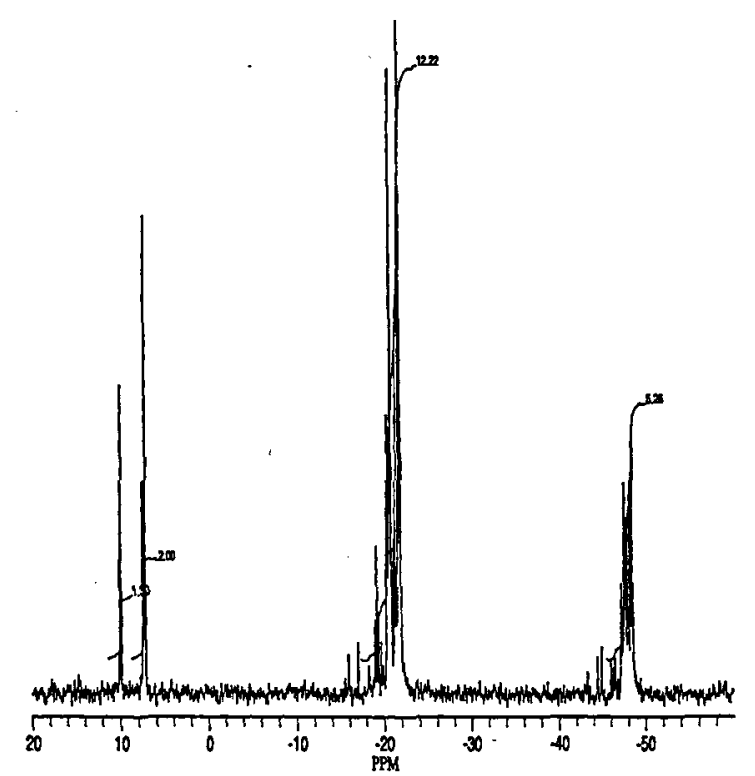

FIGURE $7{ }^{29}$ Si NMR spectrum of radiolabeled PDMDPS oil. 


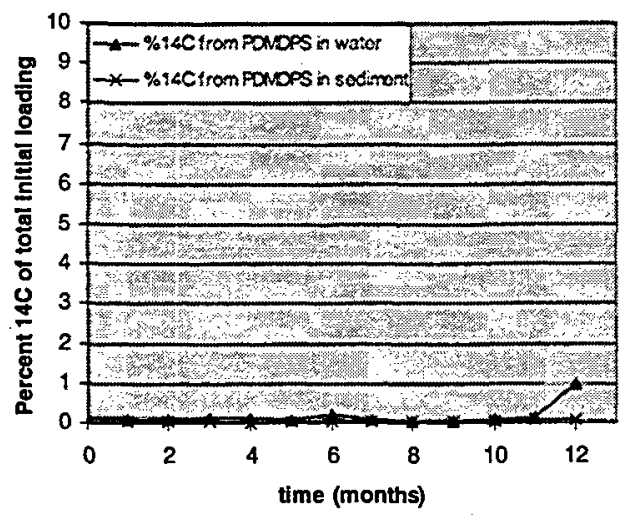

FIGURE 8 Loss of ${ }^{14} \mathrm{C}$-labeled PDMDPS oil from a cured PDMS network in a marine environment over 1 year.

TABLE II Toxicity of a typical copper antifouling paint and PDMS fouling release coating with and without PDMDPS oil

\begin{tabular}{|c|c|c|}
\hline & $\begin{array}{l}\text { Percent leachate } \\
\text { to produce } \\
\text { LC50 in M. bahia }\end{array}$ & $\begin{array}{l}\text { Percent leachate } \\
\text { to produce } \\
\text { LC50 in M. beryllina }\end{array}$ \\
\hline $\begin{array}{l}\text { Copper ablative } \\
\text { paint }\end{array}$ & 6 & 12 \\
\hline PDMS network & 140 & $>300$ \\
\hline $\begin{array}{l}\text { PDMS network }+ \\
10 w t \% \text { PDMDPS oil }\end{array}$ & 212 & $>300$ \\
\hline
\end{tabular}

Toxicity Studies on Oil-amended Silicone Fouling Release Coatings

Toxicity tests were carried out on $M$. bahia and $M$. beryllina by exposure to leachate after removal of silicone and copper ablative coating strips (Table II). A $100 \%$ leachate concentration refers to a sample in which one strip of coating had been immersed, a $200 \%$ concentration refers to a sample in which twice as much coating had been immersed in the same volume of water, and a $300 \%$ concentration refers to a water sample in which three times the amount of coating had been immersed. The coating containing PDMDPS oil required $212 \%$ leachate to produce a $50 \%$ lethal response (LC50) in M. bahia, while PDMS with no oil required $140 \%$ leachate to produce an LC50. The copper paint required only $6 \%$ leachate to produce an LC50 in $M$. bahia. Neither silicone coating formulation produced a lethal response in M. beryllina, while the copper-containing formulation required only $12 \%$ leachate to produce an LC50. These results showed that, compared to copper used in traditional antifouling coatings, silicone fouling release coatings with or without free PDMDPS oil are substantially less toxic to test organisms.

\section{CONCLUSIONS}

Silicone coatings are not antifouling coatings but rather fouling release coatings that can be easily cleaned. The addition of PDMDPS oil to a PDMS coating further decreases the adhesion of barnacles and certain species of oysters, as determined from data collected from several North American sites and in Hawaii. The environmental impact of these coatings is minimal since oil does not significantly deplete from the coating and there is little associated toxicity. Future challenges include increasing both the fouling release characteristics and the durability of silicone coatings.

\section{Acknowledgments}

Our sincerest thanks go to Bill Richards, Jim Kelley, Owen Harblin, Karen Poole, Jim Resue, Brian Nedved, Kate DeAngelis, Carlos Perez, Steve Wax, and Hal Guard for invaluable discussion and data. This project was funded under DARPA contract number N00014-96-C0145.

\section{References}

Baier R E (1980) Substrata influences on adhesion of microorganisms and their resultant new surface properties: In: Bitton G, Marshal K (eds) Adsorption of Microorganisms to Surfaces. John Wiley and Sons, New York, pp 59-104

Baier R E, Meyer A E (1992) Surface analysis of foulingresistant marine coatings. Biofouling 6: 165-180 
Bausch G G, Tonge J S (1996) Silicone technology for fouling release coating systems. Proc Watërborne High-Solids Powder Coat Symp 23: $340-353$

Bleile H R, Rodgers S (1989) Marine coatings. In: Brezinski D, Miranda T J (eds) Federation Series on Coatings Technology. Federation of Societies for Coating Technology, Philadelphia, pp 14-28

Brady R (1997) In search of non-stick coatings. Chem Ind (Lond) 6: 219-222

Callow M E, Pitchers R A, Santos R (1988) Non-biocidal antifouling coatings. In: Houghton $D \mathrm{R}$, Smith $\mathrm{R} \mathrm{N}$, Eggins $\mathrm{HO} \mathrm{W}$ (eds) Biodeterioration 7. Elsevier Applied Science, Oxford, pp 43-48

Carpenter J, Burnell T, Carroll K, Serth-Guzzo J, Stein J, Truby K (1998) Advances in nontoxic silicone biofouling release coatings. Proc Silicones Coatings Conf II, Orlando, FL

Cleary J J, Stebbing A R D (1985) Organotin and total tin in coastal waters of South West England. Mar Pollut Bull 16: $350-355$

Edwards D P, Nevell T G, Plunkett B A, Ochiltree B C (1994) Resistance to marine fouling of elastomeric coatings of some poly(dimethylsiloxanes) and poly(dimethyldiphenylsiloxanes). Int Biodeterior Biodegrad 34: 349-359

Electric Power Research Institute (1989) Non-toxic foul release coatings. EPRI report GS-6566

Finzel W A, Vincent H L (1996) Silicones in coatings. In: Brezinski D, Miranda T J (eds) Federation Series on Coatings Technology. Federation of Societies for Coating Technology, Blue Bell, PA pp 30-34

Goupil D W, DePalma V A, Baier R E (1973) Prospects for nontoxic fouling-resistant paints. Proc 9th Ann Conf Marine Technol Soc, pp 445-458

Griffith J (1992) Nontoxic marine antifouling coatings. US patent 847401

Kaelble DH (1970) Dispersion-polar surface tension properties of organic solids. J Adhesion 2: 66-81

Kannan K, Senthilkumar K, Loganthan B G, Takahashi S, Odell D K, Tanabe S (1997) Elevated accumulation of tributylin and its breakdown products in bottlenose dolphins (Tursiops truncatus) found stranded along the US Atlantic and Gulf coasts. Environ Sci Technol 31: 296-301
Meyer A E, Baier R E, Forsberg R L (1994) Field trials of nontoxic fouling-release coatings. Proc 4th Int Zebra Mussel Conf, Report No TR-104029. Electric Power Research Institute, Palo Alto, CA, pp 273-290

Meyer A E, Baier R E, Forsberg R L (1995) Degradation of nontoxic fouling-release coatings as a result of abrasion and long-term exposure. Proc 5th Int Zebra Mussel and Other Aquatic Nuisance Organisms Conf, pp 337-342

Meyer A, Baier R E, Kohl J, Singer I L, Griffith J, Haslbeck E, MontemaranoJ A, Ross A, Schultz M, Swain G (1997) Duplex foul-release coatings (Environmental Security Technology Certification program: advanced nontoxic antifouling coatings technology demonstration). NSWCCD-TR-64-95/15

Milne A (1977a) Coated marine surfaces. UK patent 1470465

Milne A (1977b) Anti-fouling marine compositions. US patent 4025693

Milne A, Callow M E (1985) Non-biocidal antifouling processes. Trans I Mar E (C) 97, Conf 2, Paper 37: 229-233

Nevell T G, Edwards D P, Davis A J, Pullin R A (1996) The surface properties of silicone elastomers exposed to seawater. Biofouling 10: 199-212

Newby B, Chaudhury M, Brown H (1995) Macroscopic evidence of the effect of interfacial slippage on adhesion. Science 269: 1407-1409

Rice S L, Diaz A F, Minor J C, Perry P A (1988) Absorption of silicone oil by a dimethylsiloxane elastomer. Rubber Chem Technol 61: 194-204

Stebbing A R D (1985) Organotins and water quality - some lessons to be learned. Mar Pollut Bull 16: 383-390

Swain G W, Schultz M P (1996) The testing and evaluation of non-toxic antifouling coatings. Biofouling 10: 187-197

Swain G W, Griffith J R, Bultman D, Vincent H L (1992) The use of barnacle adhesion measurements for the field evaluation of non-toxic foul release surfaces. Biofouling 6: 105-114

Truby K E, Celia J A, Burnell T B, Carroll K M, Stein J, Harblin O M, Serth-Guzzo J (1999) Advanced nontoxic fouling release coatings: ESTCP final report. ESTCP contract N00014-95-C6024

Walker I (1998) Non-toxic fouling control systems. Pitture Vernici Eur 13: 17-22 